\title{
Onboard Determination of Submicromolar Nitrate in Seawater by Anion-Exchange Chromatography with Lithium Chloride Eluent
}

\author{
Masahiro MARuo, ${ }^{* \dagger}$ Takashi DoI, ${ }^{* *}$ and Hajime OBATA** \\ * School of Environmental Science, The University of Shiga Prefecture, \\ Hassaka, Hikone, Shiga 522-8533, Japan \\ **Ocean Research Institute, The University of Tokyo, Minamidai, Nakano, Tokyo 164-8653, Japan
}

\begin{abstract}
Ion-exchange chromatography using a high-capacity anion exchanger with UV detection was applied to the determination of nitrate in seawater. Major ions in seawater samples did not affect the peak shape and the retention time of the nitrate when an alkaline metal cation-chloride solution was used as an eluent at high concentrations $(0.5-2 \mathrm{~mol} / \mathrm{l})$. At a wavelength of $220 \mathrm{~nm}$, the peak of bromide was very small because of low absorption, while its separation from the nitrate peak was good at high concentrations. Among the eluents tested, lithium chloride gave the best separation of nitrate from bromide. It was estimated that the lithium ion had the least potential for ion-pair formation with nitrate, and its retention time was prolonged compared with the retention times when using other cations; with bromide and nitrite, such an effect was not observed. The results of shipboard seawater nitrate determination by our method in the South Pacific Ocean and Antarctic Sea showed good agreement with those by the conventional photometric method using continuous flow.
\end{abstract}

(Received February 1, 2006; Accepted July 13, 2006)

\section{Introduction}

Nitrogen is an essential element for phytoplankton growth in aquatic environments. Nitrate is the main nutrient supporting this production in the open ocean, and the supply of nitrate often controls primary production in oligotrophic areas. Excluding the high-latitude and eastern equatorial regions of the Pacific, the surface waters of the North and South Pacific Ocean from about $40^{\circ} \mathrm{N}$ to $40^{\circ} \mathrm{S}$ are relatively depleted in nitrate. In the North Pacific subtropical gyre, nitrate concentrations are typically below $10 \mathrm{nmol} / 1 .^{1}$ To understand the nitrogen cycles in the open ocean ecosystem, a sensitive analytical method to determine the nanomolar levels of nitrate in seawater is essential.

The standard method of nitrate determination in seawater is based on a flow-injection technique with spectrophotometric detection. ${ }^{2-4}$ In this method, nitrate is first reduced to nitrite in a copperized cadmium column. Nitrite is coupled with sulfanilamide to form a diazonium cation. This diazonium reacts with $N$-1-naphtylethylenediamine dihydrochloride, forming a purple azo dye whose absorbance is measured at 550 $\mathrm{nm}$. Next, the nitrite is measured independently according to the same method without reduction. Nitrate is then calculated from the difference in the concentration between [nitrate + nitrite] and nitrite. This method can be conventionally applied to the determination of nitrate and nitrite on board; its detection limit is about $50 \mathrm{nmol} / \mathrm{l}$ as [nitrate + nitrite].

A more sensitive method of nitrate analysis has been developed by utilizing the chemiluminescence of nitrogen monoxide. ${ }^{5-7}$ In this method, both nitrate and nitrite are reduced

$\dagger$ To whom correspondence should be addressed.

T. D. present address: Echigawa Plant, Takata Corporation, Echigawa, Aisho, Echi, Shiga 529-1388, Japan. to nitrous oxide in a highly acidic solution of sulfuric acid containing iron(II) ammonium sulfate and ammonium molybdate. Nitrous oxide in the solution is carried to a drying tube and reacts with ozone, resulting in chemiluminescence. The detection limit is around $2 \mathrm{nmol} / \mathrm{l}$. This measurement method also requires nitrate reduction to nitrite. By this method, Cavender-Bares et al. ${ }^{8}$ measured 2 to $10 \mathrm{nmol} / \mathrm{l}$ concentrations of [nitrate + nitrite] in surface seawater that were below the detection limit of the standard method using azo dye formation. They revealed the vertical gradients of [nitrate + nitrite] in the North Atlantic Ocean.

As a simple method, direct UV determination ${ }^{2,4,9}$ has also been examined, but often encounters interference by bromide or organic compounds, such as humic substances, which also have UV absorbance in a wavelength range similar to that of nitrate. Capillary electrophoresis ${ }^{10,11}$ is very useful because it gives high efficiency in the separation of analytes, and enables rapid analysis and the direct injection of seawater. However, the small injection volume and short path length of the detector results in a poor detection limit for nitrate and nitrite.

Ion chromatography (IC $)^{12}$ is advantageous in the determination of nitrite and nitrate because these anions can be separated from other ions, such as bromide and organic substances. However, with highly ionic matrix solutions, such as seawater samples, IC has not proven to be applicable due to peak leading and broadening caused by self-elution with major ionic species in the sample, and also by a loss of the bandcompression effect by the saturation of ion-exchange sites. In order to overcome this problem, some modifications to this IC method have been attempted. For example, removal of the chloride ion by $\mathrm{Ag}^{+}$-form cation exchange resin has been used together with conductivity detection. ${ }^{13,14}$ A high concentration sodium chloride solution was also used as an eluent to minimize the high matrix effect of chloride in seawater samples. ${ }^{15-17}$ 
However, even after these modifications, the seawater samples had to be diluted to reduce the ionic matrix, and the detection limit in many cases did not become sufficiently low to measure the nitrate concentrations in oligotrophic oceanic water. ${ }^{18}$

Problems with the IC method can be ascribed to the poor fit of the ion exchanger used in conventional ion chromatographic systems in circumstances of high-concentration eluents. Ito et al. ${ }^{19-21}$ coated an ODS bed with long-chained tetraalkylammonium to increase the ion-exchange capacity for direct injection and the determination of nitrate and other anions in seawater. Nakamura et al. ${ }^{22,23}$ successfully used a highcapacity ion exchanger (SAX, Tosoh) and sodium chloride eluent to measure the total nitrogen content in seawater as nitrate after oxidation by peroxybisulfate. In this method, it was not necessary to coat the ion exchanger or dilute the seawater samples. This method elutes sulfate, the second major anion in seawater, very quickly, and thereby shortens the analysis time, whereas sulfate is eluted after nitrate in the conventional IC conditions. Ito ${ }^{24}$ applied the SAX anion exchanger and highvolume injection $(6 \mathrm{ml})$ to the determination of iodide in seawater using sodium perchlorate as an eluent; however, this condition is not applicable to nitrate determination because the perchlorate eluent has poor selectivity compared with chloride ${ }^{25,26}$ for the separation of early-eluting anions, such as bromide, nitrite and nitrate. Hu et al. applied electrostatic ion chromatography to the direct determination of bromide and nitrate in seawater with a low detection limit, but it was difficult to vary the separation factor and retention times of the analytes. ${ }^{27}$

Recently, we investigated the eluent composition, especially counter cations in the eluent, using the SAX anion exchanger. We concluded that the lithium ion, the most hydrated cation in the alkaline metal cations used, gave the best separation of nitrate from bromide. The analytical results of real seawater samples on shipboard are described to compare these results with those obtained by conventional spectrophotometric determination using continuous flow.

\section{Experimental}

\section{Reagents}

Anion standard stock solutions were prepared by dissolving analytical-grade reagents of sodium nitrite, sodium nitrate and sodium bromide (Wako Chemicals, Japan) in ultrapure water (Milli-Q Water: MQW). Working standard solutions were prepared by diluting each stock solution by artificial seawater (ASW) before use. ASW was prepared according to Lyman and Freming's formula. ${ }^{28}$

The eluent solution was prepared by dissolving analyticalgrade lithium chloride, sodium chloride, potassium chloride, ammonium chloride and magnesium chloride hexahydrate (Wako) in MQW. The eluent was degassed by ultrasonic vibration before use. After dissolution of the reagent, the $\mathrm{pH}$ of the eluent was not modified further. The $\mathrm{pH}$ of the eluent solutions was 5 to 6 , except for that of ammonium chloride $(\sim 4)$.

\section{Apparatus}

The ion-exchange chromatograph system consisted of a Shimadzu LC10-ADvp double-plunger pump (flow rate, 0.25 $\mathrm{ml} / \mathrm{min}$ ), a Rheodyne 9125 PEEK injection valve (injection volume $125 \mu \mathrm{l}$ ), a Shimadzu UV-Visible spectrophotometric detector SPD-10AVi and a Yokogawa pen recorder 3056. The detection wavelength was fixed at $220 \mathrm{~nm}$ because absorption of bromide was reduced to $18 \%$ compared with that at $210 \mathrm{~nm}$,

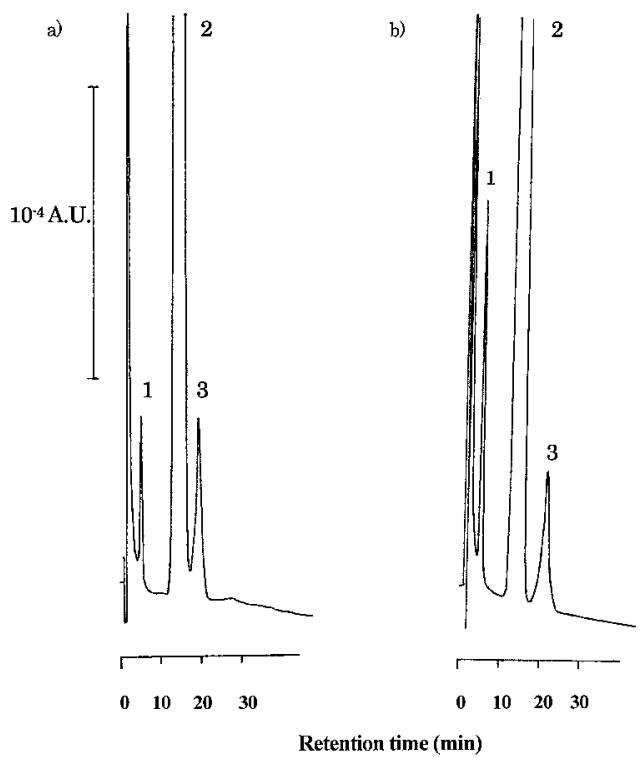

Fig. 1 Comparison of the typical chromatograms of nitrite, bromide and nitrate using lithium chloride as an eluent with sodium chloride. Eluent: (a) $1 \mathrm{~mol} / 1 \mathrm{NaCl}$; (b) $1 \mathrm{~mol} / \mathrm{l} \mathrm{LiCl}$. Sample, artificial seawater spiked with sodium nitrite and sodium nitrate solution. Anions: 1 , nitrite $(1.4 \mu \mathrm{mol} / \mathrm{l}) ; 2$, bromide $(0.83 \mathrm{mmol} / \mathrm{l}) ; 3$, nitrate $(1.0 \mu \mathrm{mol} / \mathrm{l})$. A smaller peak of nitrite in the use of sodium chloride eluent (1a) was estimated to be caused by nitrite impurity in the eluent.

while the absorption of nitrate was also reduced to about $60 \% .{ }^{18}$ The column temperature was kept at room temperature (approximately $25^{\circ} \mathrm{C}$ ). The separation column was prepared by packing Tosoh TSK-gel SAX (ion exchange capacity $1.0 \mathrm{meq} / \mathrm{g}$, diameter $5 \mu \mathrm{m})$ in a PEEK-lined stainless-steel column $(2.0 \mathrm{~mm}$ i.d. $\times 100 \mathrm{~mm}$, Upchurch, USA) with a maximum pressure of $10 \mathrm{MPa}$.

\section{Results and Discussion}

\section{Effect of counter cations in the eluent}

As reported by Nakamura et al., ${ }^{22}$ an ion exchanger with high capacity is advantageous because it enables the direct injection of seawater. In the present work, a SAX column and chloride eluent were used for determining nitrate in seawater. Although the injection volume of $125 \mu \mathrm{l}$ was relatively large for the column diameter and capacity, no peak broadening and no peak leading of nitrate were observed. In an application with 0.5 $\mathrm{mol} / \mathrm{l}$ sodium chloride as an eluent for a $100 \mathrm{~mm}$ column, the retention time of nitrate was $c a .40 \mathrm{~min}$, which is too timeconsuming for a single measurement. To shorten the measurement time, the eluent concentration was increased to 1 $\mathrm{mol} / \mathrm{l}$ upon investigation. In the use of a sodium chloride eluent, nitrate was almost separated from bromide, as shown in Fig. 1a, and the separation factor of nitrate to bromide was 1.32 . However, upon the determination of nitrate concentrations lower than $1 \mu \mathrm{mol} / \mathrm{l}$, the peak tail of bromide had the potential to interfere with the nitrate peak. A decrease in the eluent concentration enhanced the separation between these anions, ${ }^{21}$ but the detection limit also became higher. For better separation of these inorganic anions, variations of the cations were examined on the counter ions in the eluent. By fixing the concentration of chloride at $1 \mathrm{~mol} / \mathrm{l}$, alkaline, alkaline earth cations and ammonium were investigated. Among the tested 


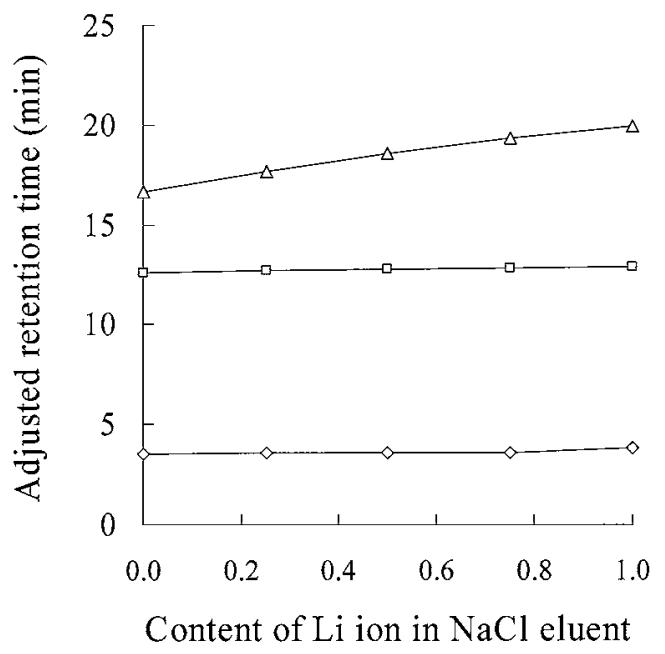

Fig. 2 Adjusted retention times of analytes vs. the variation of lithium content in the sodium chloride eluent: nitrite $(\diamond)$, bromide $(\square)$ and nitrate $(\triangle)$.

eluents, the lithium chloride eluent gave the highest separation factor of nitrate to bromide (1.55), as shown in Fig. 1b. The separation factors of nitrate to bromide for $\mathrm{Li}^{+}, \mathrm{Na}^{+}, \mathrm{K}^{+}, \mathrm{Mg}^{2+}$, and $\mathrm{NH}_{4}{ }^{+}$were $1.55,1.32,1.18,1.50$ and 1.33 , respectively.

\section{Effect of lithium ion on the separation of analytes}

To investigate the effect of the eluent concentration on the retention time of the analytes, the eluent concentration was varied in the range $0.5-2 \mathrm{~mol} / \mathrm{l}$. The slope of plots of $\log t_{\mathrm{R}}{ }^{\prime}$ versus - $\log$ eluent approximately represents the ratio of the charge of the analyte anion to that of the eluent anion (chloride ion). ${ }^{12}$ Theoretically, the slopes for all anions in this study were presumed to be -1 . The obtained slopes were $-0.88,-0.80$ and -0.85 for nitrate, bromide and nitrite, respectively, in the use of lithium chloride eluent. When using sodium chloride eluent, the slopes were $-1.04,0.83$ and -0.74 , respectively. The difference in the slopes indicates that the retention of anions is affected to some extent by ion pair formation with counter cations in the eluent. ${ }^{26,27}$ Because of the higher slope for nitrate in sodium chloride than in lithium chloride, nitrate was considered to be most affected by the ion-pair formation with sodium ion, which decreased the effective charge of nitrate. To investigate the effect of ion-pair formation to analytes, the composition of cations in the eluent was varied. Figure 2 shows the retention times of analytes in relation to the ratio of lithium ions to the total concentration of cations in a $1 \mathrm{~mol} / \mathrm{l}$ sodium chloride eluent. With an increase in the ratio of lithium ions, the retention time of nitrate increased, while that of bromide was almost constant. Given the constant retention time of bromide, the ion-pair formation of bromide with these cations was estimated to be very weak. As shown in Fig. 3, the separation factor of nitrate to bromide was increased with an increase in the ratio of lithium in the eluent. From these facts, it was suggested that the ion pair formation of nitrate with counter cations in the eluent determined the separation from bromide. The lithium ion is considered to be the most hydrated cation, and its Stokes' radius $(240 \mathrm{pm})$ is very large compared with other monovalent cations tested $\left(\mathrm{Na}^{+}, 180 \mathrm{pm} ; \mathrm{K}^{+}, 130 \mathrm{pm}\right.$; $\left.\mathrm{NH}_{4}{ }^{+}, 130 \mathrm{pm}\right){ }^{29}$ The effect of ion-pair formation is minimized by the use of the lithium or magnesium ion, which is also highly hydrated and has the second largest Stokes' radius among alkaline earth elements $(350 \mathrm{pm})$. However, the retention times

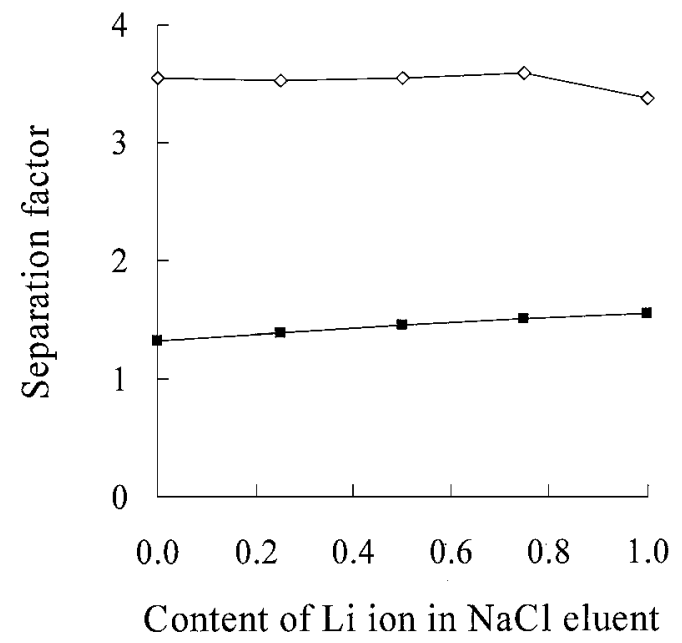

Fig. 3 Separation factors of analytes vs. the variation of lithium content in the sodium chloride eluent: separation factor of nitrate to nitrite $(\diamond)$ and separation factor of bromide to nitrate $(\boldsymbol{\square})$.

of both nitrate and bromide were increased with the use of magnesium $\left(0.5 \mathrm{~mol} / \mathrm{l}\right.$ as $\left.\mathrm{MgCl}_{2}\right)$ as a counter cation, while a variation of the retention time of bromide was very small in the use of alkaline metal cations. This fact shows that even when using lithium chloride eluent, ion-pair formation might slightly affect the elution of bromide.

The variations of the eluent $\mathrm{pH}$ in the range of 4.0 to 8.0 by adding $1 \mathrm{mmol} / \mathrm{l}$ phosphate buffer solution did not cause any significant change in the retention times and the separation of analytes. A buffer solution was not added to the eluent in the application of this method to natural water samples.

\section{Determination of real seawater samples and comparison with other methods}

Upon $125 \mu \mathrm{l}$ injection, the detection limits of nitrite and nitrate on shipboard were $2.8 \times 10^{-8} \mathrm{~mol} / \mathrm{l}$ and $1.1 \times 10^{-7} \mathrm{~mol} / \mathrm{l}$, respectively $(S / N=3$ estimated from the peak heights of $5 \times$ $10^{-7} \mathrm{~mol} / \mathrm{l}$ nitrite and $1 \times 10^{-6} \mathrm{~mol} / \mathrm{l}$ nitrate). Rolling of the vessel caused a rise in the detection limits. In a laboratory experiment, the detection limits were lowered to $1.1 \times 10^{-8}$ $\mathrm{mol} / \mathrm{l}$ and $4.0 \times 10^{-8} \mathrm{~mol} / \mathrm{l}$, respectively. A $250-\mu \mathrm{l}$ injection was also available to obtain a lower detection limit. Although peak broadening ( $21 \%$ for nitrite and $29 \%$ for nitrate in peak width) was observed, enough separation factors between each analyte were obtained, and peak broadening did not prevent a determination from being made. A vacancy peak, which corresponded to $1.2 \times 10^{-7} \mathrm{~mol} / \mathrm{l}$ nitrate, was detected at the retention time of the nitrate, because nitrate is found as an impurity in the lithium chloride reagent; these impurities must be removed by purification of the eluent in applications involving the analysis of oligotrophic surface seawater.

For $0.5 \mu \mathrm{M}$ nitrite, the variation coefficient for the peak height was estimated to be $0.6 \%$ for 5 replicate injections. The peak area of nitrite was proportional to its concentration in the range up to $0.5-4 \mu \mathrm{M}$. For $60 \mu \mathrm{M}$ nitrate, the variation coefficient for the peak height was estimated to be $0.6 \%$ for 5 replicate injections. The peak area of nitrate was proportional to its concentration of nitrate in the range up to $1-60 \mu \mathrm{M}$.

\section{Application to analysis of marine and lake water samples}

Our method was applied to nitrite and nitrate analyses of seawater samples on shipboard. The eluent used was $1 \mathrm{~mol} / \mathrm{l}$ of 


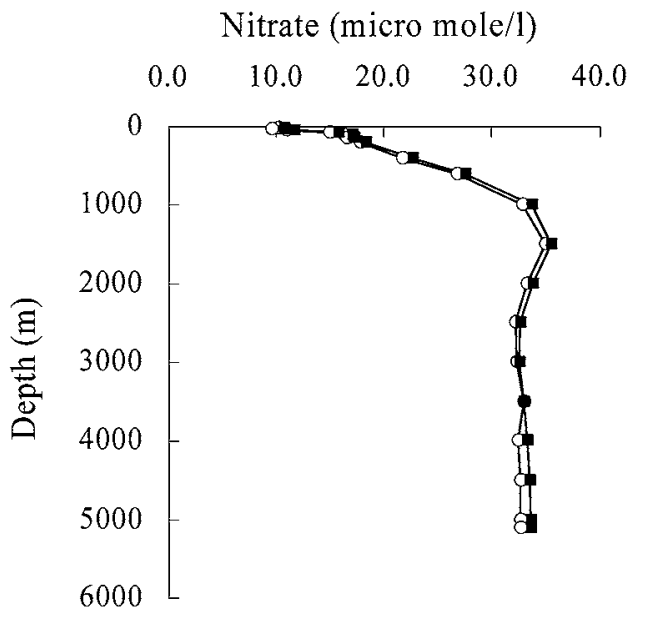

Fig. 4 Vertical distribution of nitrate at station SX-14 found using this method compared with the results of conventional analysis using conventional method: nitrate concentrations obtained by this method $(\mathrm{O})$ and conventional method ( $\mathbf{\square})$.

lithium chloride, and the $\mathrm{pH}$ was not adjusted. Seawater samples were obtained at station SX-10 $\left(67^{\circ} 12.71 \mathrm{~S}, 172^{\circ}\right.$ $40.48 \mathrm{~W}$ ) in the Antarctic Sea on Dec. 30, 2004 and station SX$14\left(50^{\circ} 00.19 \mathrm{~S}, 169^{\circ} 59.99 \mathrm{~W}\right)$ in the South Pacific Ocean on Jan. 7, 2005 on Leg-1 of the research cruise KH04-5 (Nov. 16 Dec. 5, 2003) of R. V. Hakuho-Maru (JAMSTEC, Japan). The samples were stored at $10^{\circ} \mathrm{C}$ in a refrigerator and analyzed within 3 days after sampling in the shipboard laboratory. Figure 4 shows a comparison of the vertical profiles of the nitrate concentration at SX-14 obtained by this method with those of the conventional standard method using a continuous flow system. The results of the nitrate concentration on SX-10 and SX-14 obtained by these two methods agreed well in the range of $10-34 \mu \mathrm{M}$, indicating the validity of this method (nitrate $($ this method $)=$ nitrate $($ standard method $) \times 0.979+1.081\left(R^{2}=\right.$ $0.9975, n=32)$ ).

\section{Conclusion}

An improvement of ion-exchange chromatography using a highcapacity anion exchanger and a high-concentration chloride eluent for determining nitrite and nitrate in seawater was investigated. We sought to enhance the separation of nitrate from bromide, which is the major interfering anion in seawater, by trying various counter cations in the eluent. Lithium chloride gave the best separation because of its relatively low potential for ion-pair formation with nitrate. This method was applied to the determination of nitrite and nitrate in oceanic seawater samples on shipboard. Despite the long measurement time needed, this method has advantages in the simplicity of the system and the eluent composition. By removing the effect of the vacancy peak and rolling of the vessel, this method can be used for the simultaneous determination of nitrate and nitrite in seawater at the low concentration range observed in the oligotrophic surface seawater.

\section{Acknowledgements}

The authors are grateful to the late Dr. Eiichiro Nakayama of The University of Shiga Prefecture for his discussions and for the direction he gave us, and feel sorrow for his passing. We would also like to thank the crew and researchers aboard R/V Hakuho-Maru of the Ocean Research Institute, The University of Tokyo, Japan, for their assistance with the seawater sampling and for providing the standards used for determining nitrate on leg 2 of the KH-04-5 cruise.

\section{References}

1. K. D. Karl and A. F. Michaels, "Nitrogen Cycle, Encyclopedia of Ocean Sciences", ed. J. Steele, S. Thope, and K. K. Turekian, 2001, Academic Press, London, 1876.

2. T. R. Crompton, "Analysis of Seawater", 1989, Butterworths \& Co., London, 48.

3. D. M. Karl, C. D. Winn, D. V. W. Hebel, and R. Letelier, "Hawaii Ocean Time-Series Program Field and Laboratory Protocols", 1990, 7.

4. American Public Health Association, "Standard Methods for the Examination of Water and Wastewater," 19th ed., 1995, John Wiley \& Sons, Inc., New York, 4 - 85.

5. R. D. Cox, Anal. Chem., 1980, 52, 332.

6. C. Garside, Mar. Chem., 1982, 11, 159.

7. P. Mikuska and Z. Vecera, Anal. Chim. Acta, 2003, 495, 225.

8. K. K. Cavender-Bares, D. M. Karl, and S. W. Chisholm, Deep Sea Res. I, 2001, 48, 2373.

9. K. S. Johnson and L. J. Coletti, Deep Sea Res. I, 2002, 49, 1291.

10. K. Fukushi, S. Tada, S. Takeda, S. Wakida, M. Yamae, K. Higashi, and K. Hiiro, J. Chromatogr., A, 1999, 883, 303.

11. K. Mori, W. Hu, P. R. Haddad, J. S. Fritz, K. Tanaka, H. Tsue, and S. Tanaka, Anal. Bioanal. Chem., 2002, 372, 181.

12. P. R. Haddad and P. E Jackson, "Ion Chromatography", 1990, Elsevier, Amsterdam.

13. S. Y. Tyree and M. A. O. Bynum, Limnol. Oceanogr., 1984, 29, 1337.

14. P. R. Haddad, J. Chromatogr., 1989, 482, 267.

15. S. Rokushika, K. Kihara, P. F. Subosa, and W. Leng, J. Chromatogr., 1990, 514, 355.

16. P. R. Haddad and A. R. McTaggart, J. Chromatogr., A, 1991, 546, 221.

17. A. R. McTaggart, E. C. V. Butler, P. R. Haddad, and J. H. Middleton, Mar. Chem., 1994, 47, 159.

18. T. F. Rozan and G. W. Luther III, Mar. Chem., 2002, 77, 1.77 .

19. K. Ito, E. Shoto, and H. Sunahara, J. Chromatogr., 1991, $549,265$.

20. K. Ito, Y. Ariyoshi, F. Tanabiki, and H. Sunahara, Anal. Chem., 1991, 63, 273.

21. K. Ito, Y. Takayama, N. Makabe, R. Mitsui, and T. Hirokawa, J. Chromatogr., A, 2005, 1083, 63.

22. E. Nakamura, J. Inoue, and H. Namiki, Bunseki Kagaku, 1996, 46, 711.

23. E. Nakamura, N. Miyauchi, F. Kobayashi, and H. Namiki, Bunseki Kagaku, 1999, 48, 519.

24. K. Ito, Anal. Chem., 1997, 69, 3628.

25. T. Okada, Anal. Chem., 1998, 70, 1692.

26. T. Okada, J. Chromatogr., A, 1999, 850, 3.

27. W. Hu, P. R. Haddad, K. Hasebe, K. Tanaka, P. Tong, and C. Khoo, Anal. Chem., 1999, 71, 1617.

28. J. Lyman and R. H. Fleming, J. Mar. Res., 1940, 3, 134.

29. H. Ohtaki, "Solution Chemistry: Solute-Solvent Interaction Viewed from Their Microscopic Behavior", 1985, Syokabo, Tokyo, 110. 